\title{
HAND SURGERY - LET IT FLOURISH AND DEVELOP IN BANGLADESH.
}

Being asked about existence of God, Newton said "In the absence of any other proof the thumb alone would convince me of God's existence". 1

Not only thumb, our hand as a whole is a miracle; essential for earning livelihood, for creation of art like Monalisa, for sensation- just remember the first experience of touching your beloved one.

It is an architectural wonder, unique in mechanics. Our pentadactylate hand is a structure with finely articulated cantilever digits radiating from a fixed semicircular carpal base, arranged and endowed for prehension, precision of movement, strength and sensibility --- so perfect in design that little change or specialization is needed for compliance and adaptability to the creativity so essential in human cultural development. ${ }^{2}$

This precious gift needs care. There are a large number of congenital anomalies in hand, it is vulnerable to diverse intrinsic and acquired disorders, also important for occupation related injuries----- most of them need ingenious surgical skill for correction. Specialty attention is essential and it is here that plastic surgeons can serve with the structural, functional and aesthetic requirements of this guided instrument of instruments.

\section{History and Bangladesh Perspective:}

At the turn of the 19th century, major advances are being made in general surgery but only limited attention was paid to the disabled hand. ${ }^{2}$ Principles of care were lacking; surgical intervention was unpredictable and often complicated by infection. But world war-II was the turning point.

With the experience of the war hand surgery had emerged and potentials and advantages of regional specialization had been established. In Bangladesh we are still lag behind. It is true that we have a society of hand surgeons and a couple of dedicated surgeons concentrating their efforts on hand surgery, but lots to be done.

\section{Defining the Problem:}

In UK, $20 \%$ of patient attending the accident and emergency department have hand injuries; 1/3rd of them require specialist care. ${ }^{3}$

In our country the problem seems more complicated. We need thorough baseline studies and epidemiological data to know the incidence of hand injuries and congenital anomalies; prevalence of hand deformities with functional impairment, their nature and severity, we have to measure the potential and actual effect of disabled hand on our economy, health care cost. We have to sort out their prevention, treatment and rehabilitation.

\section{What Hand Surgery Is :}

People, even some doctors may find it ridiculous. It ranges from repair of finger tip injuries to brachial plexus injuries. Needs more diverse skills than other surgical disciplines, encompassing small bone fixation, microsurgery, arthroscopy, joint replacement, reconstruction of skin, muscle, tendon and nerve, repair of blood vessels. Hand therapist's work is an integral part of hand care. Another point is - a large number of hands surgery cases can be done as day case.

\section{Requirements for Hand Surgery:}

Specific: Manpower - Surgeons, Anesthesiologist, hand therapist, non doctor staff,

Training, Operating theatre, Equipment.

General: Resource, Proper referral, Enthusiasm and Change in attitude.

\section{Manpower Development and Training:}

We have to identify and recognize our existing manpower, surgeons practicing hand surgery---plastic surgeons or orthopedic surgeons. Then we have to plan for developing new surgeons and ancillary personnel by appropriate training. Quality training with knowledge, skill and aptitude can be given in several levels.

\section{Undergraduate level:}

Concentration will be on principles of care for hand injuries and infections, splints, referral knowledge. Same things should be demonstrated during their internship in accident and emergency department. 


\section{Post graduate level:}

Plastic surgery and ortho-surgery - At least 6 months training dedicated to hand surgery should be made obligatory, So that they can take complete care of hand problems.

Other than plastic surgery and ortho-surgery in MS 2nd part, FCPS preliminary. Principles of hand surgery, position, incisions, - splints, referral knowledge. They should get basic skill of management of hand injuries and infections.

\section{For General Surgeons:}

General surgeons having MCPS, FCPS, MS degree can be offered 3 to 6 months condensed course on hand surgery regarding specific and common hand problems along with general principles. This may be an interim programme to increase our manpower till adequate number of Hand Surgeon, Plastic Surgeon or Orthopedic Surgeon are available.

Post graduation in Hand surgery: Surgeons having post graduate degree in plastic surgery, ortho-surgery or general surgery can be offered post graduate course for the duration of 2 years, it may be diploma, masters or fellowship. They will be the ultimate authority for taking care of hand problems.

It must be appreciated that suitable training from abroad in a well recognized hand surgery center will be very helpful. Simultaneously we have to train corresponding member of hand therapist and non-doctor staff.

\section{Infrastructure:}

Hand surgery unit should be built up in all medical college hospitals in divisional head quarter, with separate operation theatre, anesthesiologist, supporting staff and surgeon. Hand surgery department with provision of providing post graduate training should be established in NITOR, BSMMU, and DMCH. There should be round the clock specialist care, theatre facilities and available anesthesiologist. We cannot provide quality care to injured hand in an accident and emergency unit which is already over burdened with other injuries.

\section{Reflections:}

- Importance of hand to the well being of every individual is self evident.

- Hand injuries predominantly affect the young working population and a major source of disability.

- Best care can be ensured by regional specialization - hand surgeons.

- Plastic surgeon or orthopedic surgeon even general surgeon with proper training and adequate interest can provide the service in a well equipped hand surgery unit.

- Planning for proper hand surgery training with knowledge, skill and aptitude is a must.

- Simultaneous provision of hand therapists is essential.

- At the first phase we have to establish at least three centers/unit/department dedicated to hand surgery solely.

- We need campaign for prevention of hand injuries, first aid, early referral, address of referral centers.

- Bangladesh society of plastic surgeons, Bangladesh society of hand surgeons, BCPS, Ministry of health and family welfare, centre for accident prevention - all should come forward for development of hand surly in our country.

- Our ultimate goal is to reduce the number of preventable and correctable disability in society.

\section{References :}

1. Quoted in Des Mac Hale, Wisdom (London, 2002)

2. Littler W.J; Plastic surgeons and the development of hand surgery; Grabb \& Smith's Plastic Surgery; 6th edition; Philadelphia, Lippincott; Williams \& Wilkins, 2007.

3. www.bssh.ac.uk/ukhandsurgreport.pdf

\section{Dr. Shamim Hasan}

Assistant Professor

FCPS, MS (Plastic Surgery)

Department of Plastic Surgery.

Sir Salimullah Medical College \& Hospital. 